\title{
Recursos e capacidades de trabalho associados à renda de estabelecimentos agropecuários de produtores de tabaco do Sul do Brasil
}

\author{
Luis Augusto Araújo* \\ Marcelo Alexandre de Sá** \\ Marcia Mondardo***
}

\section{Resumo}

$\mathrm{O}$ artigo tem como objetivo compreender como os agricultores avaliam o trabalho em estabelecimentos agropecuários produtores de tabaco no Sul do Brasil, a partir da associação dos recursos e das capacidades de trabalho percebidas à renda dos anos agrícolas 2014/15 a 2017/18. É um estudo com agricultores, de abordagem de método misto, mediante aplicação de questionário, da técnica de grupo focal e de acesso a relatórios contábeis. A interpretação do material coletado seguiu os ensinamentos da estatística descritiva, da análise de correlação e de análise de conteúdo, tendo por referência a Visão Baseada em Recursos (VBR). Os resultados revelam associação positiva entre a renda e os recursos tecnológicos (máquinas, equipamentos e construções), bem como à área do estabelecimento agropecuário (agrícola explorada e total). Em contrapartida, os resultados não apontam associação à renda da disponibilidade de trabalho familiar e contratado e dos recursos humanos (idade do agricultor e grau de instrução).

Palavras-chave: capacidades de trabalho; recursos; renda.

\section{Resources and work capacities associated with the income of tobacco- producing agricultural establishments in southern Brazil}

\begin{abstract}
Abstrat
The article aims to understand how farmers evaluate work in tobacco-producing agricultural establishments in southern Brazil, from the association of perceived resources and work capacities with income from the 2014/15 to 2017/18 years is examined. It is a study with farmers, with a mixed method approach, through the application of a questionnaire, the focus group technique and access to accounting reports. The interpretation of the collected material followed the teachings of descriptive statistics, correlation analysis and content analysis, with reference to the Resource Based View (RBV). The results reveal a positive association between income and technological resources (machines, equipment and buildings), as well as the area of the agricultural establishment (exploited and total agricultural). On the other hand, the results do not indicate an association with income from the availability of family and contracted work and human resources (age of the farmer and education level).
\end{abstract}

Keywords: work capacities; resources; income.

Classificação JEL: M1, Q10

\footnotetext{
*Analista de Socioeconomia e Desenvolvimento Rural da Empresa de Pesquisa Agropecuária e Extensão Rural de Santa Catarina (EPAGRI/CEPA). E-mail: laraujo@epagri.sc.gov.br

**Analista de Socioeconomia e Desenvolvimento Rural da Empresa de Pesquisa Agropecuária e Extensão Rural de Santa Catarina (EPAGRI/CEPA). E-mail: marcelodesa@epagri.sc.gov.br

*** Estatística da Empresa de Pesquisa Agropecuária e Extensão Rural de Santa Catarina (EPAGRI/CEPA).E-mail: mmondardo@epagri.sc.gov.br.
} 


\section{Introdução}

O mundo rural brasileiro revela um processo de transformação da agricultura reconhecido por um desenvolvimento produtivo vistoso, mas socialmente controverso. Ao experimentar vida social rural menos intensa, o novo período rompe com os componentes característicos que configurou o passado rural brasileiro e permite emergir acentuado processo de vida social rarefeita nas regiões rurais (NAVARRO, 2016). As revelações acima são motivo de preocupação das pessoas em geral e, mais particularmente, de quem faz a prática da gestão dos estabelecimentos agropecuários.

Em 1954, Arthur Lewis publicou o artigo Economic development with unlimited supplies of labour, que influenciou a análise do desenvolvimento. Mais recentemente, a reversão da oferta ilimitada de trabalho para uma situação de escassez de trabalho, exterioriza uma das facetas desse novo período de desenvolvimento agrário brasileiro. Este é um acontecimento sem precedentes em nossa história agrária e um elemento nunca antes presente na organização das atividades agropecuárias (NAVARRO, 2016). Apesar das intensas transformações na agricultura, a oferta e a demanda de trabalho agrícola foram praticamente ignoradas pelas políticas públicas e também pela academia. Mais recentemente, o mercado de trabalho passou a ser motivo de reflexão à medida que suas imperfeições se tornaram perceptíveis (BUAINAIN; DEDECA, 2008; GARCIA, 2014).

Em particular, no âmbito das mudanças que ocorrem nos mercados de trabalho agrícola, as dimensões atribuídas as causas desses eventos acabam por determinar o tipo de comportamento dos agricultores (MANASSERO et al., 2006). Assim, captar a percepção que têm os agricultores com respeito às transformações no mercado de trabalho constitui um avanço na busca das causas atribuídas e, também, na compreensão da complexidade multidimensional presente na prática da gestão dos estabelecimentos agropecuários.

Em um esforço para compreender como os agricultores produtores de tabaco no Sul do Brasil se sentem em relação ao trabalho no estabelecimento agropecuário, este artigo examina a associação existente entre as capacidades percebidas de trabalho e os recursos com a renda obtida em quatro anos agrícolas. Assim, pretende-se responder a duas questões de pesquisa: i) as percepções dos agricultores sobre as capacidades de trabalho e os recursos disponíveis estão associadas à renda?; e, ii) como os agricultores se sentem em relação a disponibilidade e a qualidade do trabalho?

É um estudo com agricultores, com abordagem de pesquisa qualitativa e quantitativa, 
em que os dados primários são obtidos utilizando-se de questionário estruturado relativos às percepções dos agricultores e da técnica de grupo focal e, os dados secundários, obtidos de relatórios contábeis. No estudo, se utiliza análise de correlação para testar a relação dos recursos e das capacidades percebidas pelos agricultores à renda. Ao mesmo tempo, os insights obtidos da aplicação da técnica de grupo focal são empregados para examinar como os agricultores se sentem em relação ao trabalho no estabelecimento agropecuário. Assim, a justificativa de se fazer o acompanhamento com pesquisa qualitativa é, exatamente, melhor entender e explicar os resultados quantitativos. Nesse intento, a relevância da investigação resulta da necessidade de se compreender como se podem alavancar os recursos disponíveis e potenciar um nível de desempenho superior em estabelecimentos agropecuários que enfrentam, com frequência, um contexto de escassez de recursos.

O artigo está estruturado em quatro partes, além desta introdução. Na primeira, realizam-se uma breve reflexão sobre as transformações na agropecuária, o trabalho rural e o referencial teórico que fundamentou a elaboração do modelo de investigação. Na segunda, discorrem-se os procedimentos metodológicos adotados na pesquisa. $\mathrm{Na}$ terceira, descrevem-se as características dos estabelecimentos agropecuários estudados e apresentamse os principais resultados e sua discussão. Na última parte, apresentam-se as conclusões e sugestões para futuros estudos.

\section{0 trabalho como recurso}

Inicialmente, buscam-se caracterizar as transformações na agropecuária e suas relações com o trabalho rural. Em seguida, abordam-se os conceitos relacionados aos recursos e a heterogeneidade de renda de estabelecimentos agropecuários, sob o enfoque da Visão Baseada em Recursos (VBR).

\subsection{As transformações na agropecuária e o trabalho rural}

A estrutura produtiva agropecuária brasileira abriga estabelecimentos caracterizados pela elevada eficiência na gestão e no uso de tecnologias, assim como abriga um grande número de estabelecimentos que não possuem essas características de eficiência (ALVES; ROCHA, 2010). Esses fatos revelam parte da marcante heterogeneidade da estrutura 
produtiva agrícola, que vão inclusive repercutir direta ou indiretamente nos mercados de trabalho agrícola (GARCIA, 2014).

Em relação à via tecnológica, a modernização da agricultura foi capaz de usar as inovações químicas para aumentar a produtividade da terra e, ao mesmo tempo, intensificar o uso de inovações mecânicas, para melhorar a produtividade do trabalho. Simultaneamente, nesse processo, de um lado, ocorreu uma intensa concentração da renda e, de outro, a pobreza extrema na agricultura que se manifesta de forma aguda e regionalizada - bem delimitada no nordeste brasileiro (VIEIRA FILHO, 2017). O crescimento da produtividade revela-se como a base do desenvolvimento da agricultura brasileira (GASQUES et al., 2012). Para ressaltar a importância da tecnologia, relativamente a função de produção agrícola, observou-se que um aumento de $100 \%$ na renda bruta poderia ser explicado pela tecnologia (68\%), pelo trabalho (23\%) e pela terra (9\%) (ALVES; SOUZA; ROCHA, 2012).

A partir de 2005, o número de ocupados em atividades agrícolas no Brasil apresenta significativa redução, em razão da redução dos trabalhadores não remunerados e dos empregados sem carteira. Em 2012, a população ocupada agrícola continua representando uma parcela expressiva de 14 milhões de trabalhadores. Além disso, a população ocupada agrícola tem revelado índices elevados de desigualdade na distribuição dos rendimentos e na forma de inserção no mercado de trabalho. Mais particularmente na região Sul, entre 2005 e 2012, manifestou-se a maior redução relativa da população ocupada agrícola. O número de trabalhadores agrícolas nessa região reduziu em 1 milhão, representando $32 \%$ da população ocupada agrícola de 2005, atraídos pelas melhores oportunidades de emprego e renda nos centros urbanos (MAIA; SAKAMOTO, 2014). Além disso, contribuiu para essa redução relativa a concentração da produção e a perda da participação de pequenos estabelecimentos agrícolas em várias cadeias produtivas, a exemplo da suinocultura e avicultura (MIELE; MIRANDA, 2013).

Os elementos de análise empírica e os quadros conceituais tradicionais da economia fornecem capacidade analítica limitada para compreender as profundas mudanças estruturais do meio agrícola, que leva a implicações na estrutura e no funcionamento das organizações rurais (BOEHLJE, 1999). As teorias econômicas tradicionais sugerem que diferenças de desempenho entre as empresas devem ser incomuns e quase certamente não serão persistentes, e se existirem, são provavelmente uma manifestação das ações de comportamento em mercados imperfeitos, por parte das empresas (BARNEY; ARIKAN, 2001). 
Assim, as teorias econômicas tradicionais revelaram dificuldades para explicar as diferenças de desempenho persistentes entre empresas. Para preencher essa lacuna, emergiram diferentes correntes de pensamento que buscam desenvolver conceitos e teorias para explicar e compreender as diferenças de desempenho entre empresas. A Visão Baseada em Recursos é uma destas correntes.

\subsection{Visão baseada em recursos (VBR)}

Em seus estudos sobre o valor estratégico dos recursos, Ricardo (1817) destacava os ganhos potenciais advindos de terras que possuem produtividade superior. Em sua lógica, as terras mais produtivas terminariam diminuindo os custos médios de produção, sendo que os ganhos advindos desse diferencial passaram a ser denominados de Rendas da Terra e, posteriormente, de Rendas Ricardianas. O ganho de Rendas Ricardianas pelo uso de recursos de produtividade superior, raro e escasso representa os fundamentos da Visão Baseada em Recursos (VBR).

Na concepção de Penrose (1959), a firma é uma coleção de recursos produtivos em que a escolha do uso destes recursos ao longo do tempo depende da gestão. Assim, a firma cresce à medida que ganha eficiência em suas atividades de rotina, liberando recursos e atenção gerencial a procura de novos negócios (PENROSE, 1959). Barney (1991), que transformou a VBR numa teoria, sugeriu a definição de recurso como sendo os ativos tangíveis e intangíveis utilizados pela empresa para conceber e implementar sua estratégia (MINTZBERG et al., 2010).

Os ativos tangíveis são todos aqueles que podem ser efetivamente observados e medidos, sendo aqueles passíveis de aquisição e substituição, tais como os estoques, as instalações, os equipamentos. Além disso, os ativos tangíveis não representam vantagem duradoura à firma, na medida em que podem ser adquiridos e imitados (BARNEY, 1991; BURLAMAQUI; PROENÇA, 2009). Os ativos tangíveis podem ser categorizados em quatro grupos: Financeiros - dizem respeito à capacidade de financiamento e de gerar receita; Organizacionais - referem-se à estrutura de planejamento, controle e coordenação; Físicos como instalações físicas, equipamentos e insumos; e, Tecnológicos - como patentes, marcas registradas, direitos autorais e segredos comerciais, que são formas de tangibilizar o conhecimento (HITT; IRELAND; HOSKISSON, 2008). 
Diferentemente, os ativos intangíveis não possuem propriedades físicas, sendo de difícil observação e mensuração. Além disso, a complexidade social, a ambiguidade causal e dependência histórica fazem dos ativos intangíveis difíceis de serem copiados pelos concorrentes, contribuindo para as vantagens mais duradoras (BARNEY, 1991; BURLAMAQUI; PROENÇA, 2009; BRANCO; RODRIGUES, 2006). Os ativos intangíveis podem ser categorizados em três grupos: inovações - conhecimento técnico e científico acumulado, capacidade e disposição a inovar; recursos humanos - competências cognitivas, comportamentais, culturais e sociais; e, reputação - percepções historicamente construídas das pessoas que tem um papel direto ou indireto na gestão e resultados de uma empresa (HITT; IRELAND; HOSKISSON, 2008).

O conceito de recursos controlados por uma empresa contempla todos os ativos, capacidades, informação e conhecimento. Os recursos podem ser classificados em três categorias: (1) recursos físicos - como fábrica, equipamentos, tecnologia, localização geográfica, acesso a matérias-primas; (2) recursos de capital humano - como experiência, capacitação, inteligência, relacionamentos; e, (3) recursos organizacionais - como as rotinas que coordenam os recursos humanos e físicos da empresa (BALESTRIN; VERSCHOORE, 2016; MINTZBERG, 2010). Na perspectiva da VBR, as vantagens competitivas ocorrem a partir de recursos que sejam de domínio e de privilégio de determinada organização (WERNERFELT, 1984; PETERAF, 1993).

$\mathrm{Na}$ abordagem baseada em recursos, o segredo reside na compreensão das relações entre os recursos e capacidades e sua rentabilidade como fonte de vantagem competitiva e uma estratégia que explore as especificidades únicas da organização. Segundo o enfoque da VBR, uma estrutura para análise estratégica deve partir de uma avaliação dos recursos, da identificação das capacidades da firma, de uma avaliação do potencial de geração de renda de recursos e capacidades, da seleção de uma estratégia para explorar os recursos e capacidades e, por último, na identificação de lacunas de recursos que precisam ser preenchidas (GRANT, 1991, p.115 apud BARBOSA, 2013, p. 33). Os recursos e capacidades se constituem o centro da formulação de estratégia.

De acordo com a VBR, os recursos empregados pelas firmas se caracterizam pela oferta altamente inelástica e assim originam rendas econômicas. Nesse enquadramento, a criatividade e a habilidade da mão-de-obra são exemplos disso, apesar de sua oferta do ponto de vista quantitativo não ser inelástica. Ainda no segmento agrícola, o estabelecimento agropecuário pode se diferenciar ao se beneficiar de recursos naturais únicos (fonte de água ou tipo de solo, por exemplo) ou mesmo de um aprendizado particular (BARNEY; 
ARIKAN, 2001). De forma geral, os estabelecimentos agropecuários controlam um conjunto de recursos que variam de um estabelecimento para o outro.

A VBR propala a heterogeneidade em termos de recursos e capacidades, para explicar as diferenças ao nível do desempenho entre organizações (BERNARDINO; SANTOS, 2018). Em resumo, a VBR preconiza a historicidade do estabelecimento agropecuário singular na explicação de seu desempenho em dado momento, reconhecendo a interdependência temporal na obtenção de lucro pelos estabelecimentos agropecuários. Adianta-se que, nas páginas seguintes, não se pretende considerar todas as variáveis e recursos determinantes da renda, mas os que serão utilizados não reduzem a relevância dos resultados para os estabelecimentos agropecuários estudados e, nem tão pouco, para os demais.

\section{Material e método}

A presente pesquisa assumiu características de estudo quantitativo e qualitativo, exploratório e descritivo. O emprego de métodos mistos se justifica pela complexidade do problema abordado pelo artigo, a possibilidade de obtenção de mais insights e por favorecer uma maior compreensão do problema de pesquisa (CRESWELL, 2010). A amostragem foi intencional composta por 237 estabelecimentos agropecuários da Região Sul do Brasil que participam do programa "Propriedade sustentável1", distribuídos nas regiões representadas na Figura 1.

\footnotetext{
${ }^{1}$ O programa "Propriedade Sustentável" objetiva apoiar ações de capacitação gerencial e sustentável do agronegócio na pequena propriedade rural. Este programa resulta de um convênio entre a Secretaria de Estado da Agricultura e da Pesca de Santa Catarina, a Empresa de Pesquisa Agropecuária e Extensão Rural de Santa Catarina, a Souza Cruz e as Federações dos Trabalhadores na Agricultura dos estados de Santa Catarina, Paraná e Rio Grande no Sul.
} 
Figura 1 - Localização dos estabelecimentos agropecuários participantes da pesquisa em Santa Catarina, Paraná e Rio Grande do Sul, por município polo.

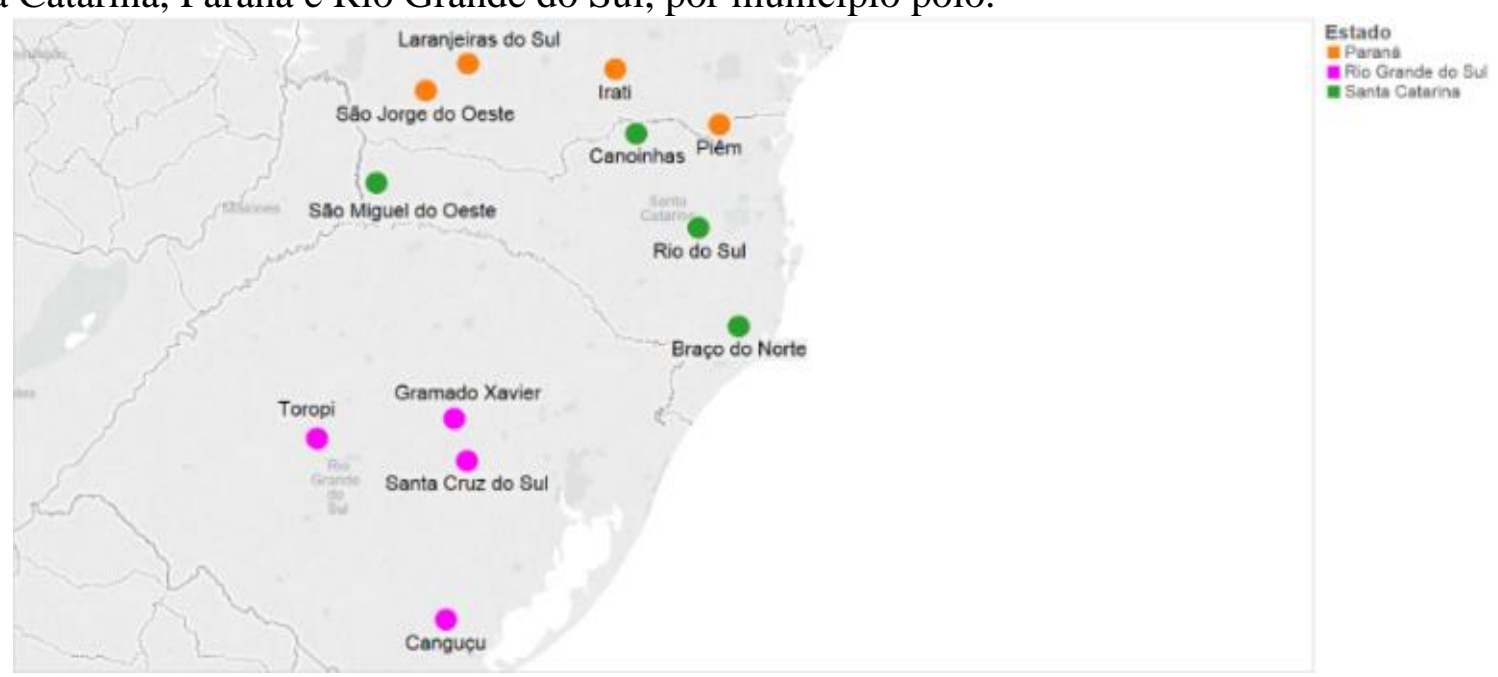

Fonte: Villazon-Montalvan et al. (2017).

\subsection{Coleta de dados}

Os dados primários foram coletados por meio da aplicação de questionário, visando ter a sua percepção sobre um conjunto de variáveis e por meio da aplicação do método de grupo focal ao conjunto de agricultores participantes deste estudo. O questionário contemplou tópicos relacionados a caracterização socioeconômica dos estabelecimentos e questões amplamente apontadas como determinantes pela bibliografia que tratam do tema, buscando-se fazer as adequações para o público objeto de estudo. O questionário foi concebido seguindo a abordagem da Análise SWOT que é uma ferramenta utilizada para fazer análise de cenário (ou análise de ambiente) e para verificar a posição estratégica da empresa no seu ambiente (FERREIRA et al., 2010). Na aplicação do questionário, cada variável relacionada ao trabalho foi classificada pelos agricultores como fortaleza ou fraqueza. Em seguida, solicitava-se a manifestação do entrevistado quanto a importância da variável nas práticas de gestão: Sem importância; Pouco importante; Importante; e, Muito importante. As respostas a cada variável foram ponderadas atribuindo-as valores de 0 a 3 , nessa ordem, de acordo com o grau de importância.

Foram realizadas doze reuniões para aplicação do grupo focal, distribuídas equitativamente entre os estados, com 19 a 20 pessoas em cada sessão. Cada grupo focal contou com um moderador, que perguntou aos agricultores: Como a disponibilidade e a qualidade da mão de obra familiar, ou contratada, afetam a gestão do estabelecimento? No 
início da aplicação do grupo focal foram pactuadas regras, assim definidas: as perguntas devem ser respondidas individualmente; o respondente identifica-se pelo nome; o respondente que não tiver opinião formada sobre a pergunta, deve manifestar-se dessa forma; e, a qualquer momento, os respondentes poderão solicitar maiores explicações sobre as perguntas.

Os dados de renda dos estabelecimentos agropecuários foram obtidos através de monitoramento, por meio do programa Contagri@, da EPAGRI, com auxílio de técnicos capacitados para este fim. A Renda da operação agrícola $\left(\operatorname{Roa}^{2}\right)$ por Unidade de trabalho homem (Uth) ${ }^{3}$ foi utilizada para representar a renda dos anos agrícolas 2014/15, 2015/16, 2016/17 e 2017/18, sendo atualizadas pelo IGP-di para junho de 2018, afim de permitir a comparabilidade entre os anos.

\subsection{Análise dos dados}

O método de análise de conteúdo foi usado para compor os resultados do método de grupo focal, consistindo no desmembramento do texto em categorias agrupadas e compreendeu três fases: (1) pré-análise - seleção do material transcrito dos 12 grupos focais e leitura flutuante; (2) exploração do material - realizada através do recorte de texto das narrativas dos agricultores comparáveis e o estabelecimento de categorias temáticas; e, por último (3) interpretação e inferências, ressaltando os aspectos considerados semelhantes e diferentes no entendimento dos agricultores sobre as variáveis relacionadas ao trabalho no estabelecimento agropecuário (SILVA, 2012; BARDIN, 2011).

Os dados de renda dos anos agrícolas foram organizados numa planilha eletrônica Excel@, no SAS@ Analytics 9.4, e tratados com estatísticas descritivas e correlação. Para o cálculo dos índices das variáveis qualitativas referentes às percepções dos agricultores, foram calculados para cada observação um indicador para cada variável, adaptado de Araújo et al. (2017). Para a realização do teste de correlação das variáveis referentes à capacidade de trabalho com a renda foi reorganizado o ranqueamento, conforme mostra a Figura 2.

\footnotetext{
${ }^{2}$ Roa é a diferença entre a renda bruta e os custos reais. Os custos reais são todos os custos do estabelecimento agropecuário, incluindo a depreciação, com exceção da remuneração da mão-de-obra familiar e dos juros sobre o capital próprio (ARAÚJO, 2009).

${ }^{3}$ Uth corresponde a um adulto que trabalha 8 horas por dia, durante 300 dias por ano. Equivale ao aporte de trabalho de uma pessoa adulta em tempo integral, no estabelecimento agropecuário, durante um ano (ARAÚJO, 2009).
} 
Assim, o espectro de variação do grau de importância varia de zero (um extremo), situação de percepção de fraqueza avaliada como de muita importância, a sete (outro extremo), situação de percepção de fortaleza avaliada como sendo de muita importância.

Figura 2 - Pontuação de cada resposta possível das variáveis relacionadas ao trabalho, reorganizados para a realização do teste de correlação com a renda.

\begin{tabular}{|cccc|cccc|}
\hline $\begin{array}{c}\text { Muito } \\
\text { importante }\end{array}$ & Importante & $\begin{array}{c}\text { Pouco } \\
\text { importante }\end{array}$ & $\begin{array}{c}\text { Sem } \\
\text { Fraqueza }\end{array}$ & $\begin{array}{c}\text { Sem } \\
\text { importância }\end{array}$ & $\begin{array}{c}\text { Pouco } \\
\text { importância } \\
\text { importante }\end{array}$ & $\begin{array}{c}\text { Importante } \\
\text { Fortaleza }\end{array}$ & $\begin{array}{c}\text { Muito } \\
\text { importante }\end{array}$ \\
\hline
\end{tabular}

Fonte: Adaptado de Araújo et al. (2017).

Para testar a associação de variáveis e recursos relacionados ao trabalho e a renda do estabelecimento, foram agrupados em quatro categorias: (1) Percepções sobre as capacidades de trabalho - disponibilidade de mão de obra familiar e contratada; disponibilidade de benfeitorias e construções; disponibilidade de máquinas e equipamentos; área total da propriedade e área explorável; e, utilização de tecnologias de produção; (2) Recursos físicos - Custos reais/Uth; Superfície agrícola útil (Sau); Área total; Unidade de trabalho homem familiar (Uth familiar); Unidade de trabalho homem assalariada (Uth assalariada); Unidade de trabalho homem total (Uth Total); (3) Recursos tecnológicos: Capital total/Uth; Capital máquinas e equipamentos/Uth; Capital construções/Uth; e, Rendimento das atividades: Tabaco estufa; Tabaco galpão; Soja safra; Milho safra; Cebola; Bovinocultura de leite; e, (4) Recursos de capital humano - idade do principal gestor do estabelecimento agropecuário; e, escolaridade do principal gestor.

$\mathrm{Na}$ análise dos valores do coeficiente de correlação, adotou-se o seguinte critério em relação à força de associação: $\pm 0,71$ a $\pm 1,00$ - alta; $\pm 0,41$ a $\pm 0,70$ - moderada; $\pm 0,21$ a \pm 0,40 - pequena, mas definida; e, $\pm 0,01$ a $\pm 0,20$ - leve, quase imperceptível (adaptado de HAIR JR. et al., 2005).

\section{Resultados e discussão}

Na primeira seção, descrevem-se as características dos estabelecimentos e o perfil socioeconômico do agricultor e sua família. Na segunda seção, revelam-se a associação entre as capacidades percebidas de trabalho pelos agricultores e a renda. Na terceira seção, 
apresentam-se os dados referentes a como os agricultores avaliam o trabalho no estabelecimento agropecuário. Por fim, na última seção, explicam-se os motivos que levaram aos resultados e suas implicações.

\subsection{Características dos estabelecimentos e perfil socioeconômico}

A Tabela 1 apresenta a média e desvio padrão de indicadores econômicos, da presença de recursos físicos e do rendimento das principais atividades dos estabelecimentos agropecuários pesquisados, para os anos agrícolas 2014/15, 2015/16, 2016/17 e 2017/18. A Renda da operação agrícola média dos estabelecimentos agropecuários por ano agrícola, estão relativamente próximos, em torno de $\mathrm{R} \$ 28.946,00$ por Uth. Os resultados não deixam de causar certa surpresa, considerando-se as particularidades do setor agrícola de dependência do clima, da ocorrência de pragas e doenças e da volatilidade de preços dos produtos e insumos.

No entanto, um desvio padrão médio de $\pm \mathrm{R} \$ 15.462,00$ revela a variabilidade da renda dentro do mesmo ano agrícola. Em decorrência disso, admitindo uma distribuição normal em torno da média ( $\mathrm{R} \$ 28.946,00 \pm 15.462,00), 68 \%$ dos estabelecimentos possuem renda dentro desse intervalo. De outro lado, isto significa que $32 \%$ do total dos estabelecimentos possuem renda acima de $\mathrm{R} \$ 44.408,00$ e renda abaixo de $\mathrm{R} \$ 13.484,00$ por Uth.

Em termos da média e desvio padrão dos recursos físicos disponíveis para os quatro anos, destaca-se:

i. Em relação a dimensão da exploração, as unidades pesquisadas possuem área total do estabelecimento agropecuário de 19,4 ha \pm 12,6 e uma superfície agrícola útil (área explorada) de 14,4 ha $\pm 10,1$ ha, com pequenas diferenças de média entre os estados;

ii. No tocante à dimensão de trabalho, as unidades pesquisadas têm a presença física de 2,5 Uth familiar $\pm 0,9$ e contratam 0,25 Uth assalariada $\pm 0,29$;

iii. Em relação à dimensão do capital da exploração agropecuária, os estabelecimentos empregam um total de $\mathrm{R} \$ 183.279,00 / \mathrm{Uth} \pm 134.369,00$, dos quais apresentam a seguinte composição: $\mathrm{R}$ \$ 19.875,00 \pm 22.674,00 de capital construções e R $\$ 34.848,00 \pm$ 30.938,00 de capital máquinas e equipamentos (além dos anteriores, o capital da terra e o capital de giro compõe a diferença para o valor do capital total do estabelecimento agropecuário);

iv. De maneira geral, os rendimentos das atividades agrícolas médios e seu desvio padrão 
exibem um determinado padrão de ocorrência, apesar das influências do ano agrícola. Particularmente, chama a atenção as atividades Milho safra $(95 \mathrm{sc}$ de $60 \mathrm{~kg}$ por hectare \pm 66) e Bovinocultura de leite (9.303 litros de leite por hectare de pasto \pm 8.373 ), que além de revelar alterações no rendimento médio nos anos considerados, exibiu um desvio padrão mais alto relativamente às demais atividades agropecuárias (respectivamente, $70 \%$ em relação à média do Milho safra e $90 \%$ para Bovinocultura de leite). Por exemplo, a atividade Tabaco estufa obteve $2.736 \mathrm{~kg} / \mathrm{ha} \pm 715$, exibindo um desvio padrão médio comparativamente mais baixo (26\% em relação à média do Tabaco estufa);

v. Tendo por base os quatro anos agrícolas e o número total de observações ( $\mathrm{N}=923), 68 \%$ dos estabelecimentos agropecuários pesquisados cultivam Tabaco estufa, 54\% Milho safra, 31\% Tabaco galpão, 24\% Soja safra e 22\% Bovino leite. Dependendo da região ou estado da federação, outras atividades aparecem com alguma frequência, tais como a Bovinocultura mista e de corte e o cultivo da Cebola (essa última, atividade presente no Alto Vale catarinense).

A descrição do perfil socioeconômico do agricultor e sua família tem por base o questionário aplicado em 2016. Naquele ano, entre os 875 membros das famílias participantes da pesquisa, 471 são do sexo masculino (53,8\% do total), 398 do sexo feminino $(45,5 \%)$ e 6 não responderam $(0,7 \%)$. Na estrutura etária do conjunto de membros das famílias dos estabelecimentos agropecuários ocorre o predomínio de pessoas adultas entre 26 e 60 anos (56,2\% do total). A faixa etária mais jovem até 25 anos, contempla 36,8\% do total, enquanto as pessoas com mais de 60 anos representam 6,2 \% do total. Para os próximos anos, esta última faixa etária deverá receber intensa ampliação (crescimento em termos relativos), relativamente às demais faixas.

Em termos de grau de instrução dos membros das famílias dos estabelecimentos agropecuários, a categoria "ensino fundamental incompleto" revela a maior presença, com 53,8\% do total de membros das famílias, e a categoria de "ensino médio completo" aparece em segundo lugar, com 18,8\%, seguida da categoria "ensino fundamental completo" ( $1^{\circ}$ ao $9^{\circ}$ ano) com 11,3\%. Apenas 13 pessoas, 1,5\% do total, admitem possuir ensino superior completo. Em relação ao tipo de atividade exercida, 58,2\% do total de membros das famílias admitem dedicação exclusiva às atividades agropecuárias, 11,6\% dedicação parcial e 3,5\% dedicação exclusiva às atividades não agropecuárias. 
Tabela 1 - Média e desvio padrão de indicadores econômicos, da presença de recursos físicos e tecnológicos por Uth, por ano agrícola.

\begin{tabular}{|c|c|c|c|c|c|c|c|c|c|}
\hline \multirow{3}{*}{ Indicadores econômicos } & \multicolumn{2}{|c|}{ Ano 2014/15 } & \multicolumn{2}{|c|}{ Ano 2015/16 } & \multicolumn{2}{|c|}{ Ano 2016/17 } & \multicolumn{2}{|c|}{ Ano $2017 / 18$} & \multirow{2}{*}{\begin{tabular}{|c}
$\mathrm{N}^{*}$ \\
Total \\
\end{tabular}} \\
\hline & Média & \multirow[t]{2}{*}{ DP } & \multirow[t]{2}{*}{ Média } & \multirow[t]{2}{*}{ DP } & \multirow[t]{2}{*}{ Média } & \multirow[t]{2}{*}{ DP } & \multirow[t]{2}{*}{ Média } & \multirow[t]{2}{*}{ DP } & \\
\hline & \multirow[b]{2}{*}{28.445} & & & & & & & & \\
\hline Renda da operação agrícola & & \pm 14.367 & 24.989 & \pm 13.443 & 31.556 & \pm 16.720 & 30.723 & \pm 16.299 & 923 \\
\hline Renda bruta & 50.460 & \pm 24.615 & 47.979 & \pm 23.178 & 55.411 & \pm 22.632 & 55.948 & \pm 28.400 & 923 \\
\hline Custos reais & 22.015 & \pm 13.446 & 22.989 & \pm 13.970 & 23.855 & \pm 16.466 & 25.225 & \pm 16.961 & 923 \\
\hline \multicolumn{10}{|l|}{ Recursos físicos } \\
\hline Área explorada (em ha) & 13,5 & $\pm 8,5$ & 14,4 & $\pm 9,9$ & 15,1 & $\pm 11,1$ & 14,6 & $\pm 10,9$ & 923 \\
\hline Área total (em ha) & 18,8 & $\pm 11,3$ & 19,3 & $\pm 12,4$ & 20,1 & $\pm 13,4$ & 19,7 & $\pm 13,2$ & 923 \\
\hline Uth familiar & 2,5 & $\pm 1,0$ & 2,5 & $\pm 0,9$ & 2,5 & $\pm 0,9$ & 2,5 & $\pm 0,9$ & 923 \\
\hline Uth assalariada & 0,3 & $\pm 0,3$ & 0,2 & $\pm 0,2$ & 0,3 & $\pm 0,2$ & 0,3 & $\pm 0,4$ & 563 \\
\hline \multicolumn{10}{|l|}{ Recursos tecnológicos } \\
\hline \multicolumn{10}{|l|}{ Rendimento } \\
\hline Tabaco estufa (kg/ha) & 2.975 & \pm 622 & 2.195 & \pm 567 & 2.876 & \pm 781 & 2.881 & \pm 595 & 625 \\
\hline Tabaco galpão (kg/ha) & 2.232 & \pm 601 & 1.837 & \pm 513 & 2.692 & \pm 488 & 2.301 & \pm 567 & 288 \\
\hline Milho safra (sc60/ha) & 94 & \pm 47 & 76 & \pm 36 & 117 & \pm 79 & 92 & \pm 85 & 498 \\
\hline Soja safra (sc60/ha) & 51 & \pm 13 & 50 & \pm 17 & 64 & \pm 19 & 58 & \pm 16 & 218 \\
\hline Cebola (kg/ha) & 21.106 & \pm 7.721 & 11.798 & \pm 5.817 & 23.584 & \pm 6.618 & 15.894 & \pm 7.252 & 34 \\
\hline Bovino de leite (litros/SFP) & 8.384 & \pm 6.457 & 8.609 & \pm 6.948 & 8.985 & \pm 8.555 & 11.468 & \pm 11.034 & 199 \\
\hline \multicolumn{10}{|l|}{ Capital (em mil Reais/Uth) } \\
\hline - Total & 187,49 & $\pm 144,42$ & 186,8 & $\pm 132,28$ & 163,48 & $\pm 105,26$ & 195,11 & \pm 149.51 & 923 \\
\hline - Construções & 21,67 & $\pm 26,67$ & 21,7 & $\pm 25,98$ & 19,42 & $\pm 21,35$ & 16,77 & \pm 14.54 & 923 \\
\hline - Máquinas e equipamentos & 33,75 & $\pm 30,18$ & 34,68 & $\pm 31,06$ & 30,46 & $\pm 26,30$ & 40,46 & \pm 34.9 & 923 \\
\hline
\end{tabular}

Fonte: Elaboração dos autores (2019), com base nos dados obtidos do Contagri@).

Além disso, 17,2\% eram estudantes, 3,8\% aposentados e 5,8\% enquadraram-se em outras situações. Por último, em relação à disponibilidade de computador, 94,1\% dos estabelecimentos agropecuários possuíram um ou mais computadores na sua unidade. Entre os entrevistados, $21,5 \%$ admitiram possuir dois ou mais computadores no seu estabelecimento, sendo que do total de membros das famílias (875), 47,6\% admitiram utilizar a internet.

\subsection{Associação das capacidades percebidas de trabalho e dos recursos à renda}

Nesta seção, revela-se a presença de associação das capacidades percebidas pelos agricultores, da presença de recursos físicos, de recursos de capital humano e de recursos tecnológicos à renda dos estabelecimentos agropecuários. Antes disso, descreve-se brevemente as percepções dos agricultores sobre distintas variáveis relacionadas ao trabalho. 
O grau de importância e a percepção em termos de fortaleza e fraqueza das variáveis relacionadas ao trabalho atribuídas pelos agricultores constam da Tabela 2.

Tabela 2 - Percepção e grau de importância (GI) ${ }^{4}$ de variáveis relacionadas ao trabalho atribuídas pelos agricultores da Região Sul do Brasil.

\begin{tabular}{|c|c|c|c|c|c|c|c|c|c|}
\hline \multirow[b]{2}{*}{ Quanto a disponibilidade/uso } & \multicolumn{4}{|c|}{ Fraqueza } & \multicolumn{4}{|c|}{ Fortaleza } & \multirow{2}{*}{\begin{tabular}{|c|} 
GI \\
Total
\end{tabular}} \\
\hline & $\mathrm{SC}$ & PR & RS & Subtotal & $\mathrm{SC}$ & PR & RS & Subtotal & \\
\hline Mão de obra familiar e contratada & 73 & 73 & 92 & 238 & 132 & 109 & 116 & 357 & 595 \\
\hline Benfeitorias e construções & 57 & 45 & 32 & 134 & 147 & 146 & 166 & 459 & 593 \\
\hline Máquinas e equipamentos & 45 & 43 & 46 & 134 & 153 & 154 & 151 & 458 & 592 \\
\hline Área explorada e da propriedade & 94 & 89 & 54 & 237 & 116 & 96 & 146 & 358 & 595 \\
\hline Tecnologias de produção & 29 & 34 & 75 & 138 & 168 & 158 & 104 & 430 & 568 \\
\hline
\end{tabular}

Fonte: Pesquisa de campo (2016).

Os agricultores revelaram uma percepção de fraqueza mais intensa quanto a disponibilidade de trabalho e da área da propriedade e da área agrícola explorada. Relativamente aos demais estados, os agricultores do Rio Grande do Sul admitiram uma fraqueza mais intensa à disponibilidade de trabalho. Nesse mesmo sentido, os agricultores catarinenses admitiram uma fragilidade maior relacionada ao tamanho da propriedade e área agrícola explorada.

Em outra perspectiva, os agricultores revelaram uma percepção de fortaleza mais intensa às benfeitorias e construções" (459) e às máquinas e equipamentos (458). Deve-se observar ainda que as mesmas possuem uma avaliação relativamente similar, independente do estado da federação considerado. A tecnologia de produção aparece como fortaleza numa posição intermediária (430), mais intensa em Santa Catarina (168) e menos intensa no Rio Grande do Sul (104). Por último, a disponibilidade de trabalho, a área da propriedade e a área agrícola explorada receberam grau de importância como fortaleza equivalentes entre si, respectivamente (357) e (358), mas menos valorizadas quando comparadas às demais variáveis.

Até aqui apresentou-se a frequência do grau de importância referente às capacidades percebidas de trabalho atribuído pelos agricultores. Em seguida, verifica-se sua associação a renda. A Tabela 3 mostra os Coeficientes de Correlação de Spearman (r), e as respectivas

\footnotetext{
${ }^{4}$ Grau de importância - A tabela foi elaborada a partir da somatória das pontuações de variáveis relacionadas ao trabalho no estabelecimento agropecuário. Cada variável foi respondida por 237 agricultores, que atribuíram um peso de 0 a 3 (grau de importância), podendo se obter pontuação máxima de 711.
} 
significâncias pelo teste $\mathrm{F}$, entre as capacidades percebidas pelos agricultores de variáveis relacionadas ao trabalho e a renda dos estabelecimentos agropecuários para os anos agrícolas 2014/15, 2015/16, 2016/17 e 2017/18. Mais precisamente, o ano agrícola 2015/16 compreendeu o período da aplicação do questionário sobre as capacidades percebidas.

Tabela 3 - Coeficiente de Correlação de Spearman das capacidades percebidas de variáveis relacionadas ao trabalho e a renda dos estabelecimentos agropecuários dos anos agrícolas 2014/15, 2015/16, 2016/17 e 2017/18.

\begin{tabular}{l|c|c|c|c|c|c|c|c}
\hline Percepções (sobre a) & $2014 / 15$ & $\mathrm{p}$ & $2015 / 16$ & $\mathrm{p}$ & $2016 / 17$ & $\mathrm{p}$ & $2017 / 18$ & $\mathrm{p}$ \\
\hline Disponibilidade de mão de obra familiar e & & & & & & & & \\
contratada & 0,1873 & $* * *$ & 0,2511 & $* * *$ & 0,0042 & $\mathrm{~ns}$ & 0,0151 & $\mathrm{~ns}$ \\
Disponibilidade de benfeitorias e construções & 0,2089 & $* * *$ & 0,2357 & $* * *$ & 0,2927 & $* * *$ & 0,2828 & $* * *$ \\
Disponibilidade de Máquinas e equipamentos & 0,3987 & $* * *$ & 0,3498 & $* * *$ & 0,3992 & $* * *$ & 0,2894 & $* * *$ \\
Área total e área útil explorada & 0,1494 & $* * *$ & 0,2118 & $* * *$ & 0,0859 & $\mathrm{~ns}$ & 0,0854 & $\mathrm{~ns}$ \\
Tecnologia de produção & 0,2689 & $* * *$ & 0,3062 & $* * *$ & 0,3763 & $* * *$ & 0,3128 & $* * *$ \\
\hline
\end{tabular}

Significância do teste $\mathrm{F}: * \mathrm{p}<0,10 ; * * \mathrm{p}<0,05 ; * * * \mathrm{p}<0,01 ;$ ns $=$ não significativo.

Fonte: Dados da pesquisa.

Os resultados sugerem que as percepções sobre as benfeitorias e construções, as máquinas e equipamentos e a utilização de tecnologias de produção estão relacionadas à renda, revelando um coeficiente de correlação significativos, de valor-p menor do que 0,01 , simultaneamente nos quatro anos agrícolas. Diferentemente, nos dois últimos anos, não encontramos uma relação estatisticamente significativa entre as percepções dos agricultores em relação a disponibilidade de mão de obra familiar e contratada, assim como a área total da propriedade e a área agrícola explorada. As percepções dos agricultores revelaram uma relação positiva, demonstrando que quanto mais os agricultores avaliam positivamente (como sendo uma fortaleza) cada uma dessas variáveis, maior é a renda obtida por ele.

Dado a relação positiva, cabe destacar ainda a intensidade de associação entre as capacidades relacionadas ao trabalho e a renda. As percepções dos agricultores relacionadas às máquinas e equipamentos, às benfeitorias e construções e à utilização de tecnologias de produção e o seu nível de renda possuem uma força de associação pequena, mas definida. Em alternativa, as percepções relacionadas a área da propriedade, da área agrícola explorada e da disponibilidade de mão de obra revelaram uma força de associação leve para com a renda nos anos 2014/15 e 2015/16, e de inexistência de associação nos anos 2016/17 e $2017 / 18$.

A Tabela 4 apresenta a associação dos indicadores econômicos, da presença de recursos físicos, de recursos de capital humano e de recursos tecnológicos e a renda dos estabelecimentos, por ano agrícola. Os indicadores econômicos exibiram uma relação 
sistemática com a renda nos quatro anos. Além disso, revelam uma relação positiva, indicando que, por exemplo, quanto maior a Renda bruta maior a renda auferida, em termos da Renda da operação agrícola. Particularmente, no ano 2016/17, ocorreu uma exceção: a presença de relação dos Custos reais com a renda foi inexistente. Quanto a intensidade de associação, cabe destacar que a Renda bruta possui alta força de associação, enquanto os Custos reais revelam força de associação moderada com a renda.

Tabela 4 - Coeficiente de Correlação de Pearson de indicadores econômicos, da presença de recursos físicos, de recursos de capital humano, de recursos tecnológicos e a renda dos estabelecimentos, por ano agrícola.

\begin{tabular}{|c|c|c|c|c|c|c|c|c|}
\hline & $2014 / 15$ & $\mathrm{p}$ & $2015 / 16$ & $\mathrm{p}$ & $2016 / 17$ & $\mathrm{p}$ & $2017 / 18$ & $\mathrm{p}$ \\
\hline \multicolumn{9}{|l|}{ Indicadores econômicos } \\
\hline Renda bruta (em Reais/Uth) & 0,8929 & **** & 0,8389 & $* * *$ & 0,6879 & **** & 0,8474 & **** \\
\hline Custos reais (em Reais/Uth) & 0,5661 & $* * *$ & 0,4296 & $* * *$ & $-0,0699$ & $\mathrm{~ns}$ & 0,4579 & $* * *$ \\
\hline \multicolumn{9}{|l|}{ Recursos físicos } \\
\hline - Área explorada (em ha) & 0,2348 & $* * *$ & 0,2862 & $* * *$ & 0,269 & $* * *$ & 0,2694 & $* * *$ \\
\hline - Área total (em ha) & 0,2144 & $* * *$ & 0,2553 & $* * *$ & 0,2278 & $* * *$ & 0,1989 & $* * *$ \\
\hline - Uth familiar & $-0,075$ & $\mathrm{~ns}$ & $-0,0798$ & $\mathrm{~ns}$ & $-0,1038$ & $\mathrm{~ns}$ & $-0,1143$ & * \\
\hline - Uth assalariada & 0,1619 & $*$ & 0,1214 & ns & 0,1843 & $* *$ & 0,0398 & $\mathrm{~ns}$ \\
\hline \multicolumn{9}{|l|}{ Recursos de capital humano } \\
\hline - Idade do produtor & $-0,1182$ & ns & $-0,1731$ & $*$ & $-0,1598$ & ns & $-0,388$ & $* * *$ \\
\hline - Grau de instrução & 0,2066 & $* *$ & 0,0511 & ns & 0,1633 & ns & 0,3489 & $* * *$ \\
\hline \multicolumn{9}{|l|}{ Recursos tecnológicos } \\
\hline \multicolumn{9}{|l|}{ Rendimento } \\
\hline - Tabaco estufa (kg/ha) & 0,5278 & $* * *$ & 0,5215 & $* * *$ & $-0,0915$ & ns & 0,3792 & $* * *$ \\
\hline - Tabaco galpão (kg/ha) & 0,2539 & $* * *$ & 0,1582 & ns & $-0,0788$ & ns & 0,1836 & ns \\
\hline - Milho safra (sc60/ha) & 0,3016 & $* * *$ & 0,2486 & $* * *$ & $-0,2029$ & $* *$ & 0,1554 & $\mathrm{~ns}$ \\
\hline - Soja safra (sc60/ha) & 0,2259 & $\mathrm{~ns}$ & 0,3155 & $* *$ & 0,0892 & ns & 0,0205 & ns \\
\hline - Cebola (kg/ha) & 0,4052 & $\mathrm{~ns}$ & 0,9675 & $* * *$ & 0,1485 & ns & 0,1329 & $\mathrm{~ns}$ \\
\hline - Bovino leite (litros/SFP) & 0,0222 & ns & 0,1404 & ns & 0,3028 & $* *$ & 0,4019 & $* * *$ \\
\hline \multicolumn{9}{|l|}{ Capital (em Reais/Uth) } \\
\hline - Total & 0,4572 & $* * *$ & 0,2691 & $* * *$ & 0,2886 & **** & 0,366 & $* * *$ \\
\hline - Construções & 0,4554 & $* * *$ & 0,2337 & $* * *$ & 0,2101 & $* * *$ & 0,4199 & $* * *$ \\
\hline - Máquinas e equip. & 0,4749 & $* * *$ & 0,3214 & $* * *$ & 0,2594 & $* * *$ & 0,4375 & $* * *$ \\
\hline
\end{tabular}

Fonte: Elaboração dos autores (2019), com base nos dados obtidos do Contagri@).

Significância do teste $\mathrm{F}$ : * $\mathrm{p}<0,10 ; * * \mathrm{p}<0,05 ; * * * \mathrm{p}<0,01 ;$ ns = não significativo.

Quanto a presença de recursos físicos, a área agrícola explorada e a área total do estabelecimento revelaram relação positiva e força de associação pequena com a renda, mas definida, significância estatística simultaneamente nos quatro anos agrícolas. Diferentemente, a presença física de trabalho familiar e assalariada não revelou associação com a renda, em pelo menos três dos quatro anos. Isto significa que ter mais ou menos 
trabalho não está associado a se ter mais ou menos renda.

Cabe ainda destacar os seguintes pontos: os recursos de capital humano apresentaram em pelo menos um ano significância estatística com a renda, exibindo uma intensidade pequena, mas isto não se deu nos demais anos. Além disso, quanto a direção da relação, apresentou uma relação negativa da idade do agricultor com a renda e uma relação positiva do grau de instrução com a renda; os recursos tecnológicos, no que diz respeito aos rendimentos das principais atividades, revelaram significância estatística com a renda em um ou outro ano agrícola, não ocorrendo de forma sistemática. O rendimento da atividade Tabaco estufa, que aparece com mais frequência nos estabelecimentos pesquisados $(\mathrm{N}=625$, com repetição), revelou a maior presença de relação positiva com a renda, com significância estatística em três dos quatro anos. Além do mais, entre todas as atividades agropecuárias relacionadas, o Tabaco estufa exibiu também a maior intensidade de associação com a renda, mesmo sendo de força moderada.

O rendimento da atividade Milho safra, a segunda com maior frequência nos estabelecimentos pesquisados $(\mathrm{N}=498$, com repetição), também revelou a presença de relação positiva com a renda, em três dos quatro anos, mas com uma intensidade de associação pequena, mas definida. Por último, a atividade Bovinocultura de leite $(\mathrm{N}=199$, com repetição) acusou presença de relação positiva com a renda somente nos dois últimos anos agrícolas 2016/17 e 2017/18, com intensidade de associação também pequena; e, no que diz respeito a categoria capital, tanto quando se considera o Capital total, o Capital construções e o Capital máquinas e equipamentos, foram observadas: uma força de associação pequena, mais definida, no ano 2015/16 e 2016/17; e uma força de associação moderada no ano 2014/15 e 2017/18.

Tendo em conta os resultados das associações dos recursos e percepções com a renda, na próxima seção, verifica-se como os agricultores se sentem em relação a disponibilidade e a qualidade do trabalho.

\subsection{O trabalho no estabelecimento agropecuário}

Nas questões relacionadas ao trabalho nos estabelecimentos agropecuários, pode-se verificar percepções distintas relacionadas a disponibilidade e qualidade de mão de obra e de outros recursos diretamente relacionados a ela. No mesmo sentido, os depoimentos dos agricultores participantes das sessões de grupo focais também revelaram essas distintas 
percepções.

Por meio do método de análise de conteúdo buscou-se identificar as ideias que representam as percepções dos grupos, classificando-as em categorias de análise. O Quadro 1 apresenta as principais ideias identificadas a partir dos dados coletados das sessões de grupo focal.

Quadro 1 - Categorias de análise relacionadas à disponibilidade e qualidade do trabalho

\begin{tabular}{|l|l|}
\hline Categorias Intermediárias & Categorias Iniciais \\
\hline Tecnologia & $\begin{array}{l}\text { Uso de máquinas e equipamentos, tecnologias que reduzam o esforço físico } \\
\text { do trabalho. O jovem quer maquinário que facilita a vida, trabalhos manuais } \\
\text { não querem. }\end{array}$ \\
\hline Sucessão - Jovem & $\begin{array}{l}\text { Tem que ter participação, o filho tem que estar junto, tem que ter voz } \\
\text { também. Compatibilização dos estudos com o trabalho na propriedade. }\end{array}$ \\
\hline Disponibilidade de terra & $\begin{array}{l}\text { Ampliação da produção limitada pela área. Também a sucessão e } \\
\text { permanência do jovem dependem de mais área }\end{array}$ \\
\hline $\begin{array}{l}\text { Mão de obra e legislação } \\
\text { trabalhista }\end{array}$ & $\begin{array}{l}\text { Pouca disponibilidade de mão de obra qualificada para o trabalho. Custo } \\
\text { alto e legislação dificultam ou inviabilizam a contratação mão de obra } \\
\text { eventual. Se eu tivesse mais mão de obra, poderia aumentar a minha renda, } \\
\text { não tem como! }\end{array}$ \\
\hline $\begin{array}{l}\text { Escala de produção e } \\
\text { diversificação }\end{array}$ & $\begin{array}{l}\text { O tamanho de produção é definido pela disponibilidade da mão de obra da } \\
\text { família e contratada. Diversificação exige mão de obra familiar, pouco } \\
\text { disponível. }\end{array}$ \\
\hline $\begin{array}{l}\text { Conhecimento e assistência } \\
\text { técnica }\end{array}$ & $\begin{array}{l}\text { Conhecimento e assistência técnica trazem resultados, reduz mão de obra; } \\
\text { Através da contabilidade, você vê o que dá lucro. }\end{array}$ \\
\hline
\end{tabular}

Fonte: Elaborado pelos autores (2019).

No quesito assistência técnica os agricultores pesquisados avaliaram de forma positiva os ganhos conquistados por meio de novos conhecimentos, capacitação por meio dos técnicos e troca de experiências com outros produtores. Também, a adoção de novas tecnologias de cultivo, práticas de análise de solo e correção, entre outras, na opinião dos agricultores trouxeram ganhos expressivos na produtividade, na redução de operações e de mão de obra. Exemplos de técnicas adotadas nas propriedades foram citados, o plantio em camalhão e o plantio na palha. Na avaliação dos agricultores, existe uma diferença visível na produtividade e lucratividade das propriedades participantes do Programa Propriedade Sustentável, relativamente aos demais agricultores não participantes deste programa. Esta vantagem, segundo eles, se deve a maior disponibilidade de informações contábeis, de conhecimento e presença da assistência técnica.

Os depoimentos relacionados a disponibilidade de terra para produção mostraram que nas regiões estudadas o recurso foi considerado escasso. Porém, sendo a cultura do tabaco intensiva em mão de obra, insumos e tecnologia, a mão de obra foi apontada como principal 
recurso escasso, e o recurso terra, neste caso, tornou-se um problema de menor intensidade para a maior parte das famílias. Também, como provável resultante das limitações impostas pela baixa disponibilidade de recurso trabalho nas propriedades, os depoimentos indicaram que existe uma dificuldade de ampliar o leque de explorações com vistas a reduzir riscos inerentes a atividade agrícola e diversificar a renda.

A preferência pelo trabalho dos membros da família foi identificada em praticamente todos os depoimentos, porém encontrou-se limitada por mudanças na estrutura familiar no meio rural e pelas expectativas de futuro dos jovens rurais. Nas últimas décadas tem-se verificado uma redução expressiva do número de filhos por casal, um envelhecimento da população ativa e um crescente êxodo de jovens buscando estudos, independência financeira e autonomia no meio urbano.

Agregam-se ao problema da escassez de mão de obra familiar os problemas que dificultam a sucessão nas propriedades. Os relatos colhidos apontaram para dificuldades relacionadas a participação dos jovens nas decisões, nas rendas auferidas e na possibilidade de promover mudanças, com vistas a uma possível sucessão dos negócios. Entre as principais expectativas externadas pelos jovens participantes dessa pesquisa figuraram a possibilidade de implantar inovações nos processos e atividades e a redução de esforço físico, por meio de uso de máquinas e tecnologias.

Especificamente sobre a mão de obra contratada de forma esporádica para atividades na propriedade, percebeu-se uma predominante insatisfação com a qualidade dos trabalhos executados por esses trabalhadores, o que resulta na preferência pelo trabalho familiar. Amplia a esta visão, as muitas dificuldades dos agricultores familiares em atenderem os requisitos exigidos pela legislação trabalhista. Argumentaram que o registro formal do trabalhador contratado se torna inviável, pois são muitos custos envolvidos para um período curto de trabalho.

\subsection{Discussão}

Os recursos disponíveis e as percepções dos agricultores sobre as capacidades de trabalho estão associados a renda? Como os agricultores se sentem em relação ao trabalho? $\mathrm{Na}$ busca por resposta às questões de pesquisa e sua compreensão buscou-se permanecer dentro de determinada perspectiva, sob o enfoque da VBR.

A gestão é uma atividade complexa que se dá no contexto do estabelecimento 
agropecuário, sendo determinante na escolha do uso dos recursos produtivos ao longo do tempo, na qual o emprego da mão de obra se constitui uma de suas preocupações. Neste artigo, a mescla das abordagens metodológicas qualitativas e quantitativas, ao mesmo tempo em que se complementam, permitiu avaliar diferentes facetas do fenômeno objeto de estudo e, dessa maneira, possibilitou uma resposta mais adequada às perguntas de pesquisa.

Nesse enquadramento, o agricultor ao avaliar os quesitos das variáveis relacionadas ao trabalho e declarar suas percepções pode viesar os resultados, sendo uma limitação metodológica que deve ser mencionada. Esta situação é sublinhada por Birkinshaw (2017) ao apontar que a mente humana pode levar a interpretação ilógica ou a discernimento impreciso da realidade. Apesar disso, dois aspectos são interessantes de serem ressaltados: i. as percepções dos agricultores e a forma como desenvolvem seu ponto de vista precisam ser consideradas porque elas influenciam as decisões dos agricultores e as suas escolhas estratégicas; e, ii. as questões de percepção propostas aos agricultores, possuem contrapartida em termos de seus recursos físicos e recursos tecnológicos, o que permitiu confrontar os achados.

Os estabelecimentos agropecuários participantes da pesquisa têm origem de distintas regiões, condições de solo e clima, sistemas de produção agropecuários e dotações de recursos tangíveis e intangíveis. Nessas condições, torna-se um desafio verificar associação entre variáveis, uma vez que em um ano agrícola determinada atividade foi bem, mas em outro não.

Um ponto importante a ser considerado na interpretação dos resultados dessa pesquisa, tem por base as ideias da VBR, em que importa o modo como os recursos são combinados para gerar valor e não, simplesmente, a posse de recursos (AUSTIN; SEITANIDI, 2011; MCKELVIE; DAVIDSSON, 2009). Isto significa que a geração de valor e da renda depende essencialmente das capacidades da organização (MCKELVIE; DAVIDSSON, 2009; RUMELT; SCHENDEL; TEECE, 1991). Assim, estabelecimentos agropecuários com recursos semelhantes poderão combiná-los de formas diferentes, o que leva a que cada um possua um conjunto de recursos único e distinto dos demais estabelecimentos (MEYSKENS et al., 2010; STEFFENS et al., 2009). Indo um pouco mais além, tal como defendido por Molloy et al. (2011), nem sempre os estabelecimentos agropecuários com mais recursos são aqueles que apresentam maior capacidade de criação de valor.

$\mathrm{Na}$ intenção de organizar a discussão dos resultados deste artigo, toma-se como referência a estrutura da VBR para análise estratégica preconizada por Grant (1991), que 
propôs a realização de algumas etapas. Na primeira etapa, realiza-se uma avaliação dos recursos do estabelecimento agropecuário, identificando fortalezas, fraquezas, ameaças e oportunidades, na busca do melhor emprego dos recursos. No cumprimento desta etapa, os dados obtidos a campo permitiram identificar (ainda que limitado às percepções dos agricultores, a presença de recursos físicos, de recursos de capital humano e de recursos tecnológicos) o que o estabelecimento agropecuário faz relativamente aos demais participantes do estudo.

Na segunda etapa, o enfoque da VBR para análise estratégica prevê uma avaliação do potencial de geração de renda dos recursos e capacidades. Os resultados apontados também contribuem com essa avaliação, ao identificar os recursos disponíveis e as percepções dos agricultores sobre o trabalho que estão relacionadas a renda, além da intensidade da relação (grau de resistência) e direção (negativa ou positiva). Uma das revelações mais importantes da pesquisa está na ocorrência simultânea da associação das percepções dos agricultores e da associação de recursos físicos e de capital com a renda dos estabelecimentos agropecuários. Nesse enquadramento, a pesquisa encontrou a presença de associação do capital construções e do capital máquinas e equipamentos e a renda, nos quatro anos considerados.

Da mesma forma, as percepções dos agricultores sobre as benfeitorias e construções e as máquinas e equipamentos estavam também relacionadas a renda (indicando que o risco de concluir que uma correlação existe quando, na verdade, nenhuma correlação existe, é menor que 1\%). Além disso, os agricultores revelaram uma percepção de fortaleza mais intensa exatamente para as variáveis “construções" e "máquinas e equipamentos". Assim, na medida em que os agricultores avaliaram positivamente (como fortaleza) as construções e as máquinas e equipamentos, associa-se uma renda mais elevada. O resultado revela, aqui, um potencial gerador de renda que merece um processo de reflexão com os agricultores que possibilite identificar os limites e alcances dessas revelações nos estabelecimentos agropecuários.

A pesquisa apontou coeficiente de correlação significativos, nos últimos dois anos agrícolas, entre as percepções dos agricultores sobre a disponibilidade de mão de obra familiar e contratada e a renda do estabelecimento. Na busca de explicação para esse resultado, quando se avalia a presença física de trabalho familiar e assalariada, também não se observa associação com a renda, em três dos quatro anos. Esses resultados têm, pelo menos, duas implicações práticas: (1) não se pode afirmar que ter mais ou menos trabalho a disposição do estabelecimento está associado a se ter mais ou menos renda; e, (2) os 
resultados da associação da percepção dos agricultores e da associação da disponibilidade física de mão de obra familiar e contratada e a renda, parecem revelar certa coerência entre si.

Entretanto, existe uma explicação para os resultados anteriores, que revelaram certas discrepâncias. A criatividade e a habilidade da mão-de-obra se caracterizam pela oferta altamente inelástica e assim originam rendas econômicas, apesar de sua oferta do ponto de vista quantitativo não ser inelástica. Isso permite ao agricultor se diferenciar ao se beneficiar de um aprendizado particular (BARNEY; ARIKAN, 2001). Além disso, como observado anteriormente, a simples posse do recurso de trabalho não gera valor e renda, e, sim, o modo como o trabalho familiar e trabalho contratado são combinados com os demais recursos do estabelecimento. Portanto, na busca de uma explicação da associação entre a disponibilidade de mão de obra familiar e contratada e a renda, os recursos intangíveis passam a ser relevantes.

De forma similar ao observado para a disponibilidade de mão de obra, a pesquisa não revelou associação entre as percepções dos agricultores sobre a área útil explorada e a área total do estabelecimento e a renda, nos dois últimos anos agrícolas. Por outro lado, a presença da área agrícola explorada e da área total do estabelecimento revelaram coeficientes de correlação significativos, simultaneamente, nos quatro anos agrícolas, e relação positiva e força de associação pequena com a renda, mas definida. Os agricultores revelaram que a ampliação da produção está limitada pela área e que a sucessão e a permanência do jovem dependem da disponibilidade de mais área. Assim, os resultados têm a seguinte implicação: as percepções dos agricultores sobre a área útil explorada e ao tamanho do estabelecimento agropecuário associadas a renda se mostram imprecisas, na medida em que a presença física da área útil explorada e do tamanho do estabelecimento se revelam associadas a renda, em todos os anos agrícolas.

Quanto aos recursos humanos, a pesquisa revelou que a idade do agricultor e o grau de instrução não estão associados a renda dos estabelecimentos. Isto porque, em apenas um ano agrícola, os recursos de capital humano apresentaram relação negativa da idade do agricultor e a renda e relação positiva do grau de instrução e a renda. Sem a pretensão de explicar a relação negativa com a idade, Araújo e Toresan (2018), em estudo com os mesmos agricultores, quando questionados sobre à tendência de crescimento e de envelhecimento populacional, apontam para uma percepção preponderantemente de ameaça.

Os recursos intangíveis são estratégicos para o desempenho dos estabelecimentos agropecuários, mais presentes nos recursos organizacionais e humanos (CARVALHO et al., 
2014, p. 515). Os recursos humanos intangíveis são aqueles que possibilitam formas mais efetivas para usufruir os recursos físicos, tecnológicos e financeiros. Em que pese a importância dos recursos humanos intangíveis, os resultados revelados pela pesquisa, no emprego da abordagem quantitativa e de suas variáveis testadas, não são suficientes e não permitem corroborar a afirmação anterior.

$\mathrm{Na}$ terceira etapa, prevê a seleção de uma estratégia para explorar os recursos, capacidades e competências únicas de cada estabelecimento agropecuário. O êxito da escolha da estratégia é dependente da compreensão das relações entre os recursos e capacidades e sua rentabilidade como fonte de vantagem competitiva. Assim, apesar da contribuição deste artigo em revelar os recursos físicos e as percepções dos agricultores associadas a renda dos estabelecimentos pesquisados, é preciso avançar no entendimento da relação desses recursos e capacidades e sua rentabilidade no âmbito individual de cada estabelecimento agropecuário.

Ainda nesse propósito, como explicar que o grau de instrução dos agricultores não aparece associado à renda? A explicação tem relação com o perfil dos membros das famílias, em termos de grau de instrução dos agricultores. Basta lembrar que apenas 1,5\% declararam possuir ensino superior completo e 53,8\% possuem ensino fundamental incompleto. Além do mais, no contexto dos estabelecimentos agropecuários, a identificação e análises dos recursos estratégicos não são tarefas fáceis, além do que precisam ser avaliados no contexto de cada unidade (BARNEY; CLARCK, 2007). Dessa afirmação, decorre a seguinte pergunta para reflexão: até que ponto uma mudança do grau de instrução dos agricultores se reflete em capacidades e competências ampliadas?

Finalmente, um ponto precisa ser mencionado como influenciando a heterogeneidade dos recursos e das rendas. A trajetória do estabelecimento agropecuário, fator temporal, é causa relevante de seus recursos e de como os agricultores os percebem, ao mesmo tempo em que esta trajetória restringe (ou potencializa) o seu futuro. A trajetória do estabelecimento desempenha uma função importante na construção e avaliação dos recursos pelo agricultor.

\section{Conclusão}

O presente artigo permitiu analisar as capacidades de trabalho percebidas pelos agricultores e os recursos disponíveis associados à renda dos estabelecimentos agropecuários e, simultaneamente, compreender como os agricultores avaliam o trabalho familiar e 
contratado. Quanto ao desenvolvimento da pesquisa, o emprego de método misto permitiu a identificação de convergências e divergências entre os dados qualitativos e quantitativos, e, entre as percepções dos agricultores e a presença física dos recursos, contribuindo para a produção de resultados que se complementam mutuamente. Além disso, o uso do referencial teórico da VBR contribuiu na definição das variáveis de estudo e nas discussões realizadas, bem como na sua organização.

No âmbito do estabelecimento agropecuário, verificou-se distintas percepções dos agricultores relacionadas ao trabalho e de outros recursos diretamente relacionados a ele. Os resultados da pesquisa em termos de associação entre os recursos e renda podem ser sumarizados da seguinte forma: (1) associação sistemática nos quatros anos em relação à percepção dos agricultores e correspondência no uso dos recursos tecnológicos - capital construções e capital máquinas e equipamentos - significando que na medida em que os agricultores avaliam positivamente (como fortaleza) as construções e as máquinas e equipamentos, associa-se uma renda mais elevada, e, em correspondência, os agricultores que contam com mais capital revelam uma renda mais elevada; (2) sem associação sistemática nos quatros anos em relação à percepção e correspondência no uso dos recursos físicos - disponibilidade de mão de obra familiar e contratada - significando que a associação da percepção dos agricultores e da associação da disponibilidade física de mão de obra familiar e contratada e a renda, revelam certa coerência; e, (3) sem associação sistemática nos quatros anos em relação à percepção e discrepância com o uso dos recursos físicos - área útil explorada e área total do estabelecimento agropecuário - significando que a percepção dos agricultores em relação à área agrícola explorada e à área total do estabelecimento não apresentou associação à renda, mas a presença física da área agrícola explorada e da área total do estabelecimento apresentou relação positiva e força de associação pequena à renda; e (4) sem associação - os recursos humanos - significando que a idade do agricultor e o seu grau de instrução parecem não estar associados a renda dos estabelecimentos.

A contribuição científica deste artigo decorre de um conjunto de condições promissoras: conta com uma coleta de dados primários em um número expressivo de estabelecimentos agropecuários, por um período considerável de anos; e, ousa avaliar uma relação pouco explorada entre as percepções dos agricultores, os recursos disponíveis e a renda dos estabelecimentos agropecuários. Apesar disso, dado a heterogeneidade dos recursos e a diversidade de sistemas de produção agropecuários explorados no Sul do Brasil, acredita-se na existência de um gap de conhecimento nessa área que merece ser suprido por meio de novas e amplas pesquisas. Uma importante questão de pesquisa, para ser estudada 
no futuro, emerge das discussões realizadas neste artigo: qual o impacto dos distintos recursos na renda dos estabelecimentos agropecuários? Os agricultores, os técnicos em geral e os formuladores de políticas públicas muitas vezes desejam prever o impacto dos recursos na renda e, nesse propósito, a análise de correlação, às vezes, não oferece respostas suficientes. Em tal caso, outros modelos econométricos podem ser aplicados.

\section{Referências}

ALVES, E.; ROCHA, D. P. Ganhar tempo é possível? In: GASQUES, J. G., VIEIRA FILHO, J. E. R.; NAVARRO, Z. (Orgs.). A agricultura brasileira: desempenho, desafios e perspectivas. Brasília: Ipea, 2010, cap. 11, p. 275-290.

ALVES, E.; SOUZA, G. S.; ROCHA, D. P. Lucratividade na agricultura. Revista de Política Agrícola, v. 21, n. 2, p. 45-63, 2012.

ARAUJO, L. A. Indicadores técnicos e econômicos para a gestão de propriedades rurais produtoras de fumo em Santa Catarina. Florianópolis: Epagri, 63 p., 2009. (Epagri Documentos 233).

ARAUJO, L. A.; GIEHL, A. L; FELICIANO, A. M.; RODRIGUES, C.; GRADE, M. Agronegócios familiares do Sul do Brasil: percepções do agricultor sobre o seu ambiente. Florianópolis, SC: EPAGRI 2017. 60 p. (Boletim técnico, 181).

ARAUJO, L. A.; TORESAN, L. Urbanização e envelhecimento da população na perspectiva de agricultores familiares do Sul do Brasil. In: XII Encontro de Economia Catarinense APEC. Lages - SC, 2018. Anais...Lage - SC: APEC, 2018. Disponível em: http://apec.pro.br/anais-dos-eventos/xii-encontro-de-economia-catarinense/ Acesso em: 08 mar. 2019.

AUSTIN, J.; SEITANIDI, M. Value creation in business - Nonprofit collaborations. Social Enterprise Series, Harvard Business School Working Paper, 33, 2011. Disponível em: http://www.hbs.edu/re- search/pdf/12-019.pdf Acesso em: fev., 2019.

BALESTRIN, A.; VERSCHOORE, J. Redes de Cooperação Empresarial: estratégias de gestão na nova economia. Bookman Editora, 2016.

BARBOSA, R. A.; MACHADO, A. G. C. Estratégias de inovação sob a perspectiva da Visão Baseada em Recursos: um estudo na Embrapa. Gestão \& Regionalidade (Online), v. 29, n. 87, 2013.

BARDIN, L. Análise de conteúdo. São Paulo: Edições 70, 2011.

BARNEY, J. B.; CLARK, D. N. Resource-based theory: Creating and sustaining competitive advantage. Oxford University Press on Demand, 2007.

BARNEY, J. Firm resources and sustained competitive advantage. Journal of management, v.17, n.1, p. 99-120, mar. 1991. 
BARNEY, J. B.; ARIKAN, A. M. The resource-based view: origins and implication. In: HITT, M. A. et al. (Ed.) The blackwell handbook of strategic management. Oxford: Blackwell, 2001.

BERNARDINO, S.; SANTOS, J.F. A Relevância da gestão de recursos para o desempenho - aplicação da teoria baseada nos recursos ao empreendedorismo social em Portugal. Revista Portuguesa de Estudos Regionais, $\mathrm{n}^{\mathrm{o}}$ 50, 2018. Disponível em: http://www.apdr.pt/siterper/numeros/RPER50/50.7.pdf. Acesso em: 22 fev. 2019.

BIRKINSHAW, J.; MARK, K. 25 ferramentas de gestão: um guia sobre os conceitos mais importantes ensinados nos melhores MBAs do mundo. São Paulo: HSM, 2017. 200 p.

BOEHLJE, Michael. Structural changes in the agricultural industries: how do we measure, analyze and understand them? American Journal of Agricultural Economics,v. 81, n.5, p.1028-1041, 1999.

BRANCO, M. C.; RODRIGUES, L. L. Corporate social responsibility and resource-based perspectives. Journal of Business Ethics, v.69, n. 2, p.111-132, 2006.

BUAINAIN A.M.; DEDECA, C.S. Introdução: emprego e trabalho na agricultura brasileira. In: BUAINAIN A.M., DEDECA, C. S. (Org.) Emprego e trabalho na agricultura brasileira. Brasília, DF: IICA, 2008. (Série Desenvolvimento Rural Sustentável, 9).

BURLAMAQUI, L.; PROENÇA, A. Inovação, Recursos e Comprometimento: Em direção a uma teoria estratégica da firma. Revista Brasileira de Inovação, Campinas, SP, v. 2, n. 1, p. 79-110, ago. 2009. ISSN 2178-2822. Disponível em: https://periodicos.sbu.unicamp.br/ojs/index.php/rbi/article/view/8648869/15407. Acesso em: 20 fev. 2019. doi: https://doi.org/10.20396/rbi.v2i1.8648869.

CARVALHO, D. M.; PRÉVOT, F.; MACHADO, J. A. D. O uso da teoria da visão baseada em recursos em propriedades rurais: uma revisão sistemática da literatura. Revista de Administração, 49(3), 506-518, 2014.

CRESWELL, J.W. Projeto de pesquisa: métodos qualitativo, quantitativo e misto. Porto Alegre: Artmed, 2010.

FERREIRA, M. P.; SERRA, F.A.R.; PEREIRA, M. F. Estratégia em diferentes contextos empresariais: fundamentos, modelos e perspectivas. São Paulo: Atlas, 2010.

GARCIA, J., Trabalho rural: tendências em face das transformações em curso. In: BUAINAIN, AM; ALVES. E.; SILVEIRA, JM; NAVARRO, Z. (Org.) O mundo rural no Brasil do século 21. Brasília, DF: Embrapa, 2014. p.559-590.

GASQUES, J. G.; BASTOS, E. T.; VALDES, C.; BACCHI, M. R. P. Total fator productivity in Brazilian agriculture. In: FUGLIE, K. O.; WANG, S. L.; BALL, V. E. (Orgs.). Productivity growth in agriculture: an international perspective. Oxfordshire: CAB International, 2012, cap. 7 p. 145-162.

GRANT, R. M. "The resource-based theory of competitive advantage: implications for strategy formulation." California management review, v. 33, n.3, p.114-135, 1991.

HAIR J.; BABIN B.; MONEY A.; SAMOUEL P. Fundamentos de métodos de pesquisa em administração. Bookman Companhia Ed; 2005.

HITT, M. A.; IRELAND, R. D.; HOSKISSON, R. E. Administração estratégica. Tradução da $7^{a}$ edição norte-americana. São Paulo: Cengane Learning, 2008. 
MAIA, A. G.; SAKAMOTO, C. S. A nova configuração do mercado de trabalho agrícola brasileiro. In: BUAINAIN, AM; ALVES. E.; SILVEIRA, JM; NAVARRO, Z. (Org.) O mundo rural no Brasil do século 21, Brasília, DF: Embrapa, 2014. p. 591-619.

MANASSERO, M., GARCÍA, E.; TORRENS, G.; RAMIS, C.; VÁZQUEZ, A.; FERRER, Y V. Teacher burnout: atributional aspects. Psichology in Spain, v. 10, n.1, p. 66-74, 2006. Disponível em: psychologyinspain.com/content/full/2006/full.asp?id=10007 Acesso em: 18 jan. 2018.

MCKELVIE, A.; DAVIDSSON, P. From resource base to dynamic capabilities: An investigation of new firms. British Journal of Management, 20 (1), 63-75, 2009.

MEYSKENS, M.; ROBB-POST, C.; STAMP, J.; CARSRUD, A.; e REYNOLDS, P. Social ventures from a resource-based perspective: an exploratory study assessing global Ashoka fellows. Entrepreneurship: Theory and Practice, 34 (4), 661-680, 2010.

MIELE, M.; DE MIRANDA, C. R. O desenvolvimento da agroindústria brasileira de carnes e as opções estratégicas dos pequenos produtores de suínos do Oeste catarinense no início do Século XXI. In: CAMPOS, S. K.; NAVARRO, Z. A pequena produção rural e as tendências do desenvolvimento agrário brasileiro: ganhar tempo é possível? Brasília, DF: CGEE. Embrapa Suínos e Aves, 2013.

MINTZBERG, H. Managing: desvendando o dia a dia da gestão. Porto Alegre: Bookman, 2010.

MINTZBERG, H.; AHLSTRAND, B.; LAMPEL J. Safári de estratégia: um roteiro pela selva do planejamento estratégico. $2^{\mathrm{a}}$ ed. Porto Alegre: Bookman Editora, 2010.

MOLLOY, J.; CHADWICK, C.; PLOYHART, R.; GOLDEN, S. Making intangibles "tangible" in tests of resource-based theory: A multi- disciplinary construct validation approach. Journal of Management, 37 (5), 1496-1518, 2011.

NAVARRO, Z. S. de. O mundo rural no novo século (um ensaio de interpretação). In: VIEIRA FILHO, J. E. R.; GASQUES, J. G.; CARVALHO, A. X. Y. (Org.) Agricultura, transformação produtiva e sustentabilidade. Brasília, DF: Ipea, 2016, p.25-63. Disponível em: http://ainfo.cnptia.embrapa.br/digital/bitstream/item/145922/1/160725agricultura-transformacao-produtiva-cap-01.pdf Acesso em: 5 mar. 2018.

PENROSE, E.T. The theory of the growth of the firm. New York: Wiley, 1959.

PETERAF, M. A. The cornerstones of competitive advantage: a resource-based view. Strategic Management. Journal, v.14, n.3, p.179-191, 1993. DOI: 10.1002/smj.4250140303

RICARDO, D. On the principles of political economy and taxation. V.1 of The Worksand Correspondence of David Ricardo, edited by P. Safra en collaboration with M. H. Dobb. Cambridge: Cambridge Uninersity Press, 1817.

RUMELT, R.; SCHENDEL, D.; TEECE, D. Strategic management and economics. Strategic Management Journal, 12, 5-29, 1991.

SILVA, A.H. Rituais corporativos como estratégia de legitimação dos valores organizacionais em empresas familiares. 2012. Disponível em: http://repositorio.ufsm.br/handle/1/4601 Acesso em: 26 fev. 2018. 
STEFFENS, P.; DAVIDSSON, P.; e FITZSIMMONS, J. Performance configurations over time: Implications for growth and profit-oriented strategies. Entrepreneurship: Theory and Practice, 33 (1), 125-148, 2009.

VIEIRA FILHO, J. E. R. Agricultura e indústria no Brasil: inovação e competitividade. Brasília: Ipea, 2017. 305 p.

VILLAZON-MONTALVAN, R. A.; ARAUJO, L. A.; GIEHL, A. L.; FELICIANO, A. M. Conception of managing practices as key factor to achieve rural development and sustainability in southern Brazil. European Journal of Sustainable Development, v. 6, Issue 4, Roma - Italia: di EJSD, 2017.

WERNERFELT, B. The resource-based view of the firm. Strategic Management Journal, v.5, n.2, p. 171-180, 1984. DOI: 10.1002/smj.4250050207 